\title{
La Inquisición frente a la locura en la España de los siglos XVI y XVII (I). Manifestaciones, tratamientos y hospitales.
}

The Inquisition face to madness in Spain in the XVI and XVII centuries (I). Manifestations, treatments and hospitals.

\section{Hélène Tropéa.}

${ }^{a} U F R$ d'Études Ibériques et Latino-américaines (Université PARIS III Sorbonne Nouvelle)

Centre de Recherche sur l'Espagne des XVIe et XVIIe siècles (CRES - LECEMO - PARIS III)

Correspondencia: Hélène Tropé (helenetrope@hotmail.fr)

RESUMEN: Este artículo, basado en la documentación inquisitorial del Archivo Histórico Nacional, analiza la visión que los inquisidores y sus ayudantes tuvieron de la locura y, en algunos casos, la utilización que hicieron de ésta en los siglos XVI y XVII para acallar determinadas actitudes. En la primera parte del artículo se estudian las manifestaciones y los tratamientos de la locura en el ámbito inquisitorial. Se examinan esencialmente casos de reos locos a los que los inquisidores no consideraron demasiado peligrosos políticamente, es decir reos que no eran susceptibles de contagiar sus ideas o de crear émulos. También se evocan las relaciones tensas entre los inquisidores de Toledo y el cabildo de la iglesia, de quien dependía el hospital de locos de esta ciudad ("Hospital del Nuncio"), a propósito del ingreso de reos locos.

PALABRAS CLAVE: síntomas, tratamientos, melancolía, manía, tortura, Hospital de locos de Toledo (Hospital del Nuncio).
ABSTRACT: This article, based on the inquisitorial documents of Archivo Histórico Nacional analyses the inquisitors' and their assistants' madness point of view and, in some cases, how they used it to silence certain attitudes in the XVI and XVII centuries. In the first part of the article, madness manifestations and treatments are studied in the inquisitorial field. Mad defendant cases are analysed, essentially those ones, inquisitors did not consider to be politically dangerous because the defendants were not susceptible of spreading their ideas or making rivals. Besides, regarding mad defendants' admission, the strained relationship between the Toledo inquisitors and the chapter, on which this town's mental hospital (Hospital del Nuncio) depended, is also mentioned.

KEYWORDS: Symptoms, treatments, melancholy, mania, torture, the Hospital del Nuncio de Toledo mental hospital.

En este trabajo, basado en la documentación inquisitorial del Archivo Histórico Nacional, me propongo analizar la visión que los inquisidores y sus ayudantes tuvieron de la locura y, en algunos casos, la utilización que hicieron de ésta en los siglos XVI y XVII para acallar determinadas actitudes. ${ }^{1}$

Desde el Derecho Romano, tanto civil como penal, la falta de cordura del acusado es una circunstancia atenuante, cuando no eximente de culpa. ${ }^{2}$ En el Dic-

1 El presente trabajo se inscribe en el marco de mis investigaciones precedentes sobre 'locura e Inquisición en Valencia’: Hélène Tropé, Locura y sociedad en la Valencia de los siglos XV la XVII: los locos del Hospital de los Inocentes (1409-1512) y del Hospital General (1512-1699) (Valencia: Diputación de Valencia, Centre d'Estudis d'Història Local, 1994), 183-206; 'Folie et Inquisition à Valence (1580-1699)', en: Hommage à Pierre Vilar, Association Française des Catalanistes (Paris: Éditions Hispaniques/AFC, 1994), 171-85.

2 En 1609, ante el tribunal de Granada, la locura a consecuencia de una enfermedad de perlesía contribuyó a eximir de culpa a Fray Mateo de la Puebla, de la orden de san Agustín, que había 'tratado de amores' con sus 'hijas de confesión' (AHN, Inq., leg. 1953, caja 2, exp. 55, fols 7v-8r).

Recibido: 24/10/2009; aceptado: 18/12/2009

Rev. Asoc. Esp. Neuropsiq., 2010; 30 (106), 291-310. 
cionaro de los Inquisidores publicado en Valencia en 1494, ya se distinguían varias situaciones según el momento en que sobrevenía la locura. ${ }^{3}$ Primero, si el reo enloquecía después del supuesto crimen había que darle un curador, de lo que se deduce que los inquisidores consideraban que el proceso debía seguir su curso. Segundo, se establecía que una especie de locura llamada furor conllevaba la total ignorancia de quien profería palabras heréticas. Por consiguiente, no se le podía castigar ya que, como subrayaba el canonista español, 'su locura ya lo castiga bastante'. ${ }^{4}$ Como veremos, esta irresponsabilidad del loco acarreaba muchos problemas a los inquisidores, siempre enfrentados a la dificultad de averiguar si la locura de los reos era auténtica. De ahí el carácter muy detallado de algunas relaciones de causas referidas a estos últimos.

Como ha mostrado el libro de María Cristina Sacristán sobre Nueva España, esa documentación proporciona una amplia gama de informaciones sobre la mentalidad de aquella época en relación con el tema de la locura, en especial sobre la norma y su transgresión, sobre la ortodoxia y los delitos de fe, sobre la normalidad y lo que se aparta de ella. ${ }^{5}$ Asimismo, estos procesos nos informan no sólo sobre los aspectos médicos de la demencia, sino también sobre sus facetas culturales y sociales. Son estos puntos los que abordaré en una primera parte, titulada: 'La locura según los inquisidores y sus colaboradores: manifestaciones y tratamientos'. En ella examinaré esencialmente casos de reos locos a los que los inquisidores no consideraron demasiado peligrosos políticamente, es decir reos que no eran susceptibles de contagiar sus ideas o de crear émulos.

Sin embargo, en determinados casos, los hechos y dichos de algunos reos sumieron a los inquisidores en abismos de dudas: ¿estaban o no locos? ¿fingían para escapar a su justo castigo? En una segunda parte intentaré contestar a la pregunta siguiente: '¿Locura verdadera o locura fingida?'

En una tercera parte examinaré las relaciones entre las dos instituciones relacionadas con el tema del presente estudio: Inquisición y hospital de locos. $\mathrm{Me}$ ocuparé en especial del caso toledano.

3 Louis Sala-Molins, Le dictionnaire des inquisiteurs (traducción al francés de Repertorium Inquisitorium, Valencia, 1494; Paris: Editions Galilée, 1980), 224.

4 La Instrucción 60 de Torquemada de 1484, reconducida varias veces por los Inquisidores siguientes, por ejemplo por Gaspar Isidro Argüello en 1630, ordenaba asimismo que si algún reo enloquecía antes del juicio, había que darle curador. Se deduce que el proceso debía proseguir hasta su conclusión; véase Tomás de Torquemada, Compilación de las instrucciones del Oficio de la santa Inquisición, 49 hojas, siglo XVIII (Biblioteca Nacional de Madrid, Mss/12014), fol. 124v; véase también AHN, Inq., libro 1225, fol. 453r, p. 35: '[Instrucción] 60. Dese curador a los reos que perdieren el juizio. Cómo se ha de recebir lo que los hijos o deudos de los reos alegaren en su favor'.

5 María CRistina SACRISTÁn, Locura e Inquisición en Nueva España: 1571-1760 (México: Colegio de Michoacán, Fondo de Cultura Económica, 1992). 
Finalmente, me cifraré en la suerte que conocieron aquellos reos locos a quienes los inquisidores tuvieron por susceptibles de difundir sus herejías o profecías. En especial, analizaré determinados casos en que los inquisidores utilizaron la locura como arma de poder para aislar, eliminar y excluir definitivamente a quienes consideraron peligrosos. He titulado esta cuarta parte: 'Utilización política de la locura por los inquisidores para aislar y eliminar. ¿Herejes locos o endemoniados?'

\section{La locura según los inquisidores y sus colaboradores: manifestaciones y tratamientos}

Son muy numerosos los casos en que los presos murieron o se volvieron locos en las cárceles secretas antes o durante los procesos. En los reos, encarcelados sin conocer el motivo, se creaba un fuerte sentimiento de culpa; se les conminaba a buscar en su memoria en qué, cuándo y cómo habían actuado contra la fe, y así el Santo Oficio provocaba su rápida y profunda destrucción psíquica. A consecuencia de ello, y día tras día, algunos perdían la razón. En numerosos casos era el mismo personal de la cárcel (el alcaide y su ayudante) el que informaba a los inquisidores que tal o cual recluso estaba teniendo un comportamiento raro.

En este caso, por lo general, uno de los inquisidores, junto con un notario, bajaba a la celda para cerciorarse de ello. A continuación, mandaban a los médicos del tribunal que lo visitasen. En muchas ocasiones, cuando un preso se volvía loco, lo enviaban al hospital de orates más próximo o, si no era demasiado ruidoso o violento, a alguna casa de un particular. ${ }^{6}$

Los casos de reos locos fueron todos muy diversos y también diversas y llamativas fueron las decisiones tomadas para con ellos. Sin embargo, un criterio esencial guiaba al Santo Oficio: su determinación por erradicar la herejía, y por consiguiente, castigar y aislar a los reos peligrosos por sus creencias o sus herejías, fuesen o no locos. Así, si el reo no escandalizaba demasiado, lo dejaban en la cárcel, le confiscaban sus bienes y aguardaban a que recobrara el juicio para poder aplicarle las penas ya que, como había señalado Peña, si bien no se puede ejecutar a un loco, tampoco se le puede dejar impune. ${ }^{7}$

6 Véase por ejemplo el caso de Juan López detenido en 1589 en Toledo por palabras heréticas, que alegó para su defensa que era de poco juicio. Su curador y los mismos inquisidores lo tuvieron por loco y fue llevado al Hospital del Nuncio: Julio Sierra, Procesos en la Inquisición de Toledo, 1575-1610: manuscrito de Halle (Madrid, Trotta, 2005), caso ${ }^{\circ}$ 514. Véase también el caso de la rea Francisca Rodríguez, que enloqueció y fue trasladada al hospital de orates de Toledo (AHN, Inq., leg. 2635, caja 1, exp. 10: 'Relación de causas de abril de 1654, tribunal de Granada'), o el de Gerónimo Fernández, portugués judaizante procesado por el tribunal de Granada en 1653, y llevado a casa del padre de un familiar (AHN, Inq., leg 2635, exp. 3).

7 Nicolau Eimeric, Francisco Peña, El Manual de los Inquisidores, ed. Luis Sala-Molins (trad. Luis 
¿Cuáles eran exactamente, según los documentos, las señales exteriores de la locura?, y ¿qué remedios prescribían los galenos?

\section{El caso de Ana de Acosta}

Se trata de una conversa portuguesa de 15 años, soltera, natural de Sevilla, acusada de judaizar, a quien apresó la Inquisición toledana el 26 de mayo de $1662 .{ }^{8}$ El alcaide dio la voz de alarma en febrero del año siguiente pues había encontrado a Ana desnuda y postrada. Ésta le dijo que desde hacía algunas noches recibía en su celda la visita de 'un bulto de persona vestida de blanco'. ${ }^{9}$ A instancias de los inquisidores la visitaron el médico y el cirujano del tribunal. Padecía, según ellos, 'morbo de melancolía ypocondríaca', y además tenía una gangrena en dos dedos del pie izquierdo y parte del empeine, por lo que decidieron que sería preciso cortarle muy en breve los dedos. ${ }^{10}$

Tanto en este caso como en los siguientes, encontramos en los testimonios de los médicos los discursos típicos de la época, fieles a Galeno, fundados sobre la doctrina de los cuatro temperamentos. Ésta establecía un sistema de correspondencias entre elementos, planetas, cualidades primarias, estaciones, humores, facultades y edades. ${ }^{11}$ La bilis negra o melancholia se consideraba un humor seco, de temperatura variable, que reunía cualidades opuestas (era cálido pero podía también ser frío), y provocaba síntomas muy variados. ${ }^{12}$ En los documentos procedentes de los testimonios de los médicos del Santo Oficio, encontramos un compendio de las concepciones sobre la melancolía y la filosofía de las pasiones entonces en vigor. El médico del tribunal testimonió que Ana de Acosta tenía:

una enfermedad que llaman los médicos melancolía morbo y ésta es hipocondríaca y por propia passión del zelebro, que es como una locura continuada,

\footnotetext{
Sala-Molins, Francisco Marín, de: Directorium Inquisitorum, 1376; Barcelona: Muchnik, 1983), 150-52. Véanse, por ejemplo, los casos de María Gonçález, presa por judaizante en 1676 por el tribunal de Llerena (AHN., Inq., leg. 1988, exp. 12, fols 16r-v), Melchor Núñez, preso por judaizante en 1641 por el tribunal de Granada (AHN, Inq., leg. 2106, exp. 42, fols 11v-12v) y Doña Guiomar de Biezma, procesada por judaizante en 1609 por el tribunal de Granada (AHN, Inq., leg. 1953, exp. 55, fol. 11r).

8 AHN, Inq., leg. 130, exp. 3, fols 145r-164r; leg. 3128, fol. 4r; leg. 3129, fols 2v-207r.

9 AHN, Inq., leg. 130, exp. 3, fols 145r-146r.

10 AHN, Inq., leg. 130, exp. 3, fols 150 r-150v.

11 Véase Augustin Redondo, 'La melancolía y el Quijote de 1605', Otra manera de leer el 'Quijote' (Madrid: Castalia, 1997), 121-46.

12 Christine Orobitg, L’humeur noire: mélancolie, écriture et pensée en Espagne au XVIe et au XVIIe siècle (Bethesda: International Scolars Publications, 1997).
} 
ORIGINALES Y REVISIONES

con miedo y tristeza, hecha de humores mélancólicos, y si ésta sus padres la han tenido, se curará con dificultad por ser enfermedad hereditaria. ${ }^{13}$

Según las distinciones de la época, la melancolía hipocondríaca se originaba en el vientre y en las vísceras. ${ }^{14}$ También se consideraba que las pasiones, perturbadoras del ánimo, modificaban el equilibrio de los humores. La melancolía, seca y fría, engendraba pasiones fundadas en el dolor; de ahí que se asociara con la tristeza. ${ }^{15}$ Encontramos fuertes ecos de estas teorías en el testimonio médico sobre Ana de Acosta, cuya melancolía hipocondríaca también se asocia claramente con su reclusión en una cárcel triste, fría y húmeda. Todo esto es lógico: la melancolía engendra tristeza y si, además, a un melancólico que lo es por una causa natural (su excesivo humor melancólico), se le encierra en una cárcel fría, húmeda y triste (causa no natural), su mal no puede ir sino a peor. ${ }^{16}$ Algunos médicos, siguiendo a Aristóteles, distinguían dos tipos de temperamento melancólico: uno frío y alelado, y el otro cálido, activo y muy vivo. ${ }^{17}$ A todas luces, Ana de Acosta era del primer tipo. Los médicos la describen como 'embelesada, absorta a todo, espantada, sin responder' e insisten en que '[su] curazión propia no se puede exercer por aora por ser el tiempo frío' y que 'la cárcel donde está es muy fría y húmeda y no es a propósito para la curación de dicha enfermedad'. Por ello, y con una implacable lógica, recomiendan que 'se lleve a parte cuálida' ${ }^{18}$ Asimismo, encontramos en este documento interesantes prescripciones sobre la dieta considerada adecuada para una melancólica:

se ha de prevenir el que no se haga mayor [su melancolía] comiendo alimentos calientes moderadamente, y húmedos porque esta enfermedad consiste en destemplanza seca del zelebro y los alimentos an de ser para mediodía cavezas de carnero y manos y carne de estremo del brazuelo y de la pierna; para zenas huevos frescos, almendradas, ensaladas de escarola y berrazas cozidas y el remedio más eficaz de todos por aora [es] alegrarle y dibertirla en lo que se pueda. ${ }^{19}$

3 AHN, Inq., leg. 130, exp. 3, fol. 149v.

14 Véase Orobitg, L'humeur, 97-104.

5 Orobitg, L'humeur, 33-37.

Orobitg, L'humeur, 66-67.

Orobitg, L'humeur, 57.

AHN, Inq., leg. 130, exp. 3, fol. 151v.

19 AHN, Inq., leg. 130, exp. 3, fol. 149v. Sobre la almendrada, el tratado clásico de Dioscórides aclara que las almendras amargas son secas y calientes, no así las dulces, y critica a los médicos 'que en qualquiera enfermedad y complexión, luego ordenan un almendrada al enfermo, el cual es mantenimiento pesado': Pedacio Dioscórides Anazarbeo, Acerca de la materia medicinal y de los venenos mortíferos, trad. Andrés Laguna [1556], ed. facs Pedro Laín Entralgo (Madrid: Fundación de Ciencias de la Salud, 1999), 112-13. Todo nuestro agradecimiento a José Luis Peset del CSIC por estos datos. 
La cambiaron de celda pero su gangrena fue a más y en febrero de 1663, los médicos insistieron en que había que operarla. Justo antes de trasladarla al Hospital del Bálsamo de Toledo, el 10 de febrero de 1663, la hicieron comparecer en audiencia y la absolvieron; después la operaron mutilándole dos dedos.

No cabe duda de que esta mujer, que además de melancolía tenía fiebres tercianas ('tabardillo'), estuvo en peligro de muerte; pero era una hereje y la relación de su causa muestra que los inquisidores nunca dejaron de dudar si fingía o no su enfermedad mental. ${ }^{20}$

\section{Beatriz de Campos}

La locura hizo que el proceso toledano de esta judaizante portuguesa, soltera, y presa a partir de diciembre de 1678 , se prolongase durante siete años. ${ }^{21}$ Cuatro meses después de ser arrestada, empezó a enfermar de locura y un año más tarde, la trasladaron de la cárcel secreta a una sala retirada de la enfermería del Hospital del Bálsamo, donde la atendió la enfermera mayor. A pesar de las continuas visitas de los médicos, no hizo sino empeorar. En diciembre de 1679 la ingresaron en el Hospital del Nuncio, donde permaneció durante seis años hasta que, el 5 de marzo de 1686, la trajeron de vuelta a las cárceles secretas.

La relación de su causa suministra abundante información acerca de la melancolía y de las enfermedades vinculadas con este humor. Todo empezó en abril de 1679 cuando pidió audiencia y dijo que se sentía mal, con 'unos desmayos y baydos de cabeza', síntomas a menudo relacionados con la bilis negra, de la que se pensaba que originaba desmayos y debilidad, debidos al agotamiento de la energía vital por el frío y la sequedad de dicho humor. ${ }^{22}$ Los inquisidores ordenaron que fuera visitada a menudo por el médico y el cirujano.

Éstos testificaron que padecía aferecía, o epilepsia (fol. 100r.), una enfermedad que a menudo se vinculaba a la melancolía. ${ }^{23}$ Anteriormente la habían reducido con algunos medicamentos y ligaduras fuertes, y según ellos, su salud había mejorado. Pero ahora padecía:

20 Su caso es comparable al de Leonor López, conversa portuguesa procesada en Toledo en 1670, que, según los médicos, estaba 'loca, falta de juicio, por sequedad del cerebro demasiado caliente'. Estaba furiosa, lanzaba palos y piedras por la ventana, llegando al punto de herir al hijo de otro preso. Éste y otros testimoniaron que la rea era una 'loca rematada', que alborotaba con sus gritos no sólo a toda la cárcel sino incluso al barrio entero. El médico fue a verla y aseguró que padecía 'locura confirmada' y de nuevo se recomendó su ingreso en el Nuncio. Así se hizo, y ya no se han encontrado más noticias sobre ella (AHN, Inq., leg. 3136, folios sin numerar).

21 AHN, Inq., leg. 138, caja 1, exp. 9, Toledo, 1678-1686, fols 71r-194r.

22 Véase Orobitg, L'humeur, 113-15.

23 Orobitg, L'humeur, 107-09. 
ORIGINALES Y REVISIONES

melancolía hipocondríaca, [...] que procede del útero, hígado y bazo, y está privada de razón, de la facultad rectora, y la sangre muestra esto mismo, y los demás accidentes que padece son desta misma melancolía. ${ }^{24}$

Encontramos aquí las imágenes tradicionalmente ligadas a la hipocondría: los órganos bajos, las vísceras, lo más hundido y oscuro del ser. ${ }^{25}$ No es de extrañar, pues, que acto seguido, los médicos relacionasen su melancolía con lo más vil y digno de reprobación. Es así como afirmaron que 'lo que ella habla conduce a pensar que tiene accidentes de acceso venéreo que es semen corrupto de que está dañada la madre [el útero]'. ${ }^{26}$

¿A qué podría referirse el documento con 'lo que ella habla'? Entre las 'acciones y palabras deshonestas' que se apuntan, encontramos que 'en cierta ocasión se le había puesto encima un hombre que llamaba ella Soto y que no le había hecho nada' (fol. 99r.). En sus informes orales los médicos insisten en que 'siempre está desbarriando y diciendo deshonestidades. Además ha dado en andar desnuda en carnes passeándose por la cárcel' (fol. 101r.). Constatamos así cómo en los sistemas de representación de la melancolía se establecía un vínculo entre bilis negra y lujuria que desembocaba en una amalgama de locura, pecado y lujuria en la que se mezclaba lo médico con lo religioso y lo ético. ${ }^{27}$

Sabido es que se achacaba la causa de estos males a los 'humores pecantes', por lo que no es de extrañar que el médico dijera que tenía 'humores crassos o sangre detenida' (fol. 98r.). Como se trataba de una mujer gruesa, se intentó sangrarla, mantenerla fuertemente atada, hacerle comer carne e incluso se recomendó su internamiento en el hospital de los locos. ${ }^{28}$ En tres ocasiones aplicaron esta técnica de la sangría en el pie derecho y se guardó la sangre para que la examinara el médico.

La enferma no descansaba. En consecuencia, se le recetó una bebida de adormideras que apenas surtió efecto y le practicaron nuevas sangrías. Sin embargo, la mujer no mejoraba. El diagnóstico era:

melancolía morbo e hipocondría originada de semen corrupto según las señales exteriores que le pueden percibir, con calidad venenosa, y así pudo promptamente obrar en ella aquel delirio y que la misma vehemencia, sin poderlo impedir los medicamentos, la ha pasado a manía, de que se ha puesto tan furiosa como está, resistiéndose a comer y a beber y a todo género de medicamento por la boca. ${ }^{29}$

24 AHN, Inq., leg. 138, caja 1, exp. 9, fol. 100r.

Orobitg, L'humeur, 101-04.

AHN, Inq., leg. 138, caja 1, exp. 9, fol. 100r..

Orobitg, L'humeur, 122-24.

AHN, Inq., leg. 138, exp. 9, caja 1, fols 98 r-99r.

AHN, Inq., leg. 138, exp. 9, caja 1, fol. 102 r. 
Como el médico opinó que la rea tenía la cabeza ardiente, le recetó baños atemperantes y mandó que se le cortara el pelo porque tenía mucho y muy espeso (fol. 102v.). También ordenó que le echaran unas sanguijuelas, aunque no se sabe si llegaron a aplicárselas.

En una audiencia ante el tribunal, en diciembre de 1679 (Beatriz llevaba enferma desde octubre), el médico afirmó que no sólo no había disminuido la melancolía, sino que había aparecido un principio de manía. La mujer era, por tanto, una enferma incurable (fols. 113v-114r.). No habían bastado los remedios de sangrías y baños en la cabeza, ya que además se había negado a tomar, por vía oral, las medicinas recetadas: 'por obrar su entendimiento depravadamente que es la esencia del delirio que padece en el entendimiento como es propio de esta enfermedad'.$^{30}$

La opinión de los médicos continuó siendo que había que ingresarla en el Hospital del Nuncio. Esa misma audiencia suministra datos interesantes sobre los métodos de curación de la melancolía en los hospitales de locos: 'se suelen curar [semejantes enfermedades] con tiempo y castigo y comidas de cabeza de carnero y menudos y parte cómoda de dormitorio y vestidos a propósito y asistencia de enfermeras que tienen experiencias de semejantes enfermedades y modos de curarse'. ${ }^{31}$

En los testimonios referidos a su causa, llama la atención la amalgama de delirio, religión judaica y locura. Gracias al testimonio de la mujer que la asistía sabemos que Beatriz estaba presa de un extraño delirio. A veces decía que era doncella, otras que era 'la reina de España y que maldito sea el que reina en el cielo, aquel chiquito que así la ha puesto, y que ella dice que no cree sino en los diablos, que el poderoso Dios Adonay tiene treinta y tantos nombres' (fol. 103r.).

Su cuidadora declaró que había dado puñetazos a una Santa Cruz y afirmado que San Pedro era su hijo, y que lo parió, así como a San Francisco, y a ambos los llamaba 'perros' (fol. 113v.). Ella, educada en la religión judaica, recuperaba el material religioso católico para elaborar su delirio y expresar su oposición a esta Fe. También parece significativo que los inquisidores consideraran estos delirios religiosos como locura confirmada, equiparando de alguna manera herejía y locura. ${ }^{32}$

Ahora bien, si tardaron tanto en ingresarla en el Hospital del Nuncio, es probablemente porque tenían dudas respecto a su locura.

30 AHN, Inq., leg. 138, exp. 9, caja 1, fol. 114r..

31 AHN, Inq., leg. 138, exp. 9, caja 1, fol. 114r.

32 Sobre esta equiparación del judaísmo con la locura, véase también el caso de Ana Méndez, procesada como judaizante en 1628 por el tribunal de Llerena (AHN, Inq., leg. 1987, exp. 24, fols 12r-16r). 
ORIGINALES Y REVISIONES

\section{¿Locura verdadera of fingida?}

La irresponsabilidad jurídica del loco y la consiguiente imposibilidad de castigarlo planteaba verdaderos quebraderos de cabeza al Santo Oficio, principalmente en los casos en que se sospechaba que la insania era simulada. En efecto, como lo recuerda el Manual de los Inquisidores: 'entre las diez argucias de los herejes para responder sin confesar [...], la novena consiste en simular estupidez o locura' (Manual, 150).

Pero ¿qué pasaba cuando los inquisidores se equivocaban y frente a un reo verdaderamente loco, opinaban que estaba fingiendo y lo castigaban? Es la pregunta planteada por Francisco Peña: 'El tema de la locura fingida merece particular atención. ¿Y si, por una vez, se tratase de un loco auténtico? Para tener la conciencia limpia, se someterá a tormento al loco, verdadero o falso' (Manual, 150).

Efectivamente, la Inquisición nunca vaciló en torturar a los sospechosos de simular su locura, algo que Peña justificaba arguyendo que el bien público debía prevalecer frente a la salvación del alma de un solo individuo. Entonces, esto quiere decir que si se castigaba por error a un verdadero demente tampoco era muy grave (Manual,151-52).

Así se explica que en varias ocasiones los inquisidores recurrieran a la tortura para desenmascarar a quienes pretendían estar locos. En algunos casos, como el de Bernardo López Moreno, resultó ser un método eficaz. Preso en Granada desde mayo de 1655 por judaizante, se volvió loco. Dado que algunos testigos habían declarado que más que loco era bellaco, le aplicaron el tormento y le dieron cien azotes. Confesó ser judaizante, fue admitido después a reconciliación con confiscación de bienes y abjuró. ${ }^{33}$

En otros casos, como el de Juana Carpio, la tortura fue algo menos eficaz. ${ }^{34}$ Conversa portuguesa de unos cuarenta años, vecina de Granada, procesada en Toledo por judaizante, confesó su delito. El proceso parecía encarrilado, pero el 19 de agosto de 1616, yendo el inquisidor a visitar las cárceles, la encontró haciendo locuras. El médico declaró que estaba frenética pero no tanto como para ingresarla en el hospital de los locos y se decidió a llevarla a casa de su marido.

Seis meses después, el cuñado de Juana testificó que ésta le había contado a su esposo que había fingido la locura, con lo que se ordenó su vuelta a la cárcel y la conclusión de su causa. Tampoco los testigos se pusieron de acuerdo: según unos, mentía; para otros, estaba realmente loca. El fiscal la acusó de simular maliciosamente su demencia y así la volvieron a llevar a la audiencia, donde no quiso calmarse ni responder a pregunta alguna, ni siquiera cuando le administraron veinte

33 AHN, Inq., leg. 2640, exp. 127.

34 AHN, Inq., leg. 1953, exp. 66, fols 1r-3r. 
azotes. Se le designó un curador, que afirmó que estaba loca, pero el fiscal insistió en su falsedad y ordenó que se le diese tormento. En marzo de 1618, confesó bajo tortura que su marido le había aconsejado que se fingiese demente y que no pronunciase palabra; de esta forma, ni se le confiscarían los bienes ni se le causaría daño alguno. Declaró que cuanto había afirmado eran disparates y se desdijo de todo.

Tras ser sometida a nuevos tormentos, confesó en el potro, pero a continuación negó la veracidad de esas confesiones, invalidándolas. El tribunal ordenó que se la privase de sus bienes y el caso pasó al Consejo que, el 10 de diciembre, mandó que se hiciese justicia según se había acordado. La sentencia de relajación se ejecutó el 29 de junio de 1620 .

Su caso contrasta con el de Luis Hernández, morisco vecino de Toledo, que, en 1581, fue torturado en vano. Arrestado por haber sido visto en su aposento alzando y bajando los brazos y teniendo en una olla una culebra y dos lagartos muertos, había declarado que no estaba practicando ningún rito sino preparando unos ungüentos. Los inquisidores lo tuvieron por loco y él mismo probó que había estado fuera de juicio y frenético. Le aplicaron el tormento, sin que éste permitiera averiguar si su locura era real o fingida, y se suspendió el proceso. ${ }^{35}$

Nada peor que la locura, auténtica o falsa, de los reos para los inquisidores aferrados a su tarea: castigar, cuando no eliminar, a quien se había hecho culpable de 'herética pravedad'. De esa exención -la locura- se derivaban no pocas dificultades, empezando por las dudas que les iban carcomiendo a la hora de decidir si los reos estaban o no cuerdos. En efecto, ¿cómo averiguar con certeza si un reo fingía locura o no? Para ello se podía acudir a diversas estratagemas: primero, poner al convicto un acompañante (que no fuera preso por el mismo delito, sobre todo si se trataba de judaísmo), al que después se interrogaba. Así sucedió con Benito Ferrer, preso en Toledo en noviembre de 1622, a quien pusieron no un compañero sino tres, dos de ellos además muy selectos: un eclesiástico y un médico. Interrogados después por el tribunal, declararon que el reo 'no es loco sino que finge serlo y que es hombre de muy buena capaçidad y que le tienen por bellaco hereje y no por loco'. Lo interesante es el matiz sutil que introduce el médico cuando añade que 'le a juzgado por de sano juiçio aunque tanvién le tiene por melancólico y que tiene algunas ymaxinaçiones'.${ }^{36}$ Con tanto distingo no es de extrañar que los inquisidores no siempre supieran a qué atenerse, lo mismo que el Consejo que ordenó prudentemente: 'que vaian continuando i avisando'.

Segundo, el tribunal podía pedir a los alcaides de las cárceles secretas que estuviesen atentos al comportamiento de sus reclusos e incluso que los espiasen a través de agujeros practicados en las puertas de las celdas. De esta manera, el

35 Sierra, Procesos en la Inquisición de Toledo, caso $n^{\circ} 277$

36 AHN, Inq., leg. 3079, carta del 17 de febrero de 1623. 
ORIGINALES Y REVISIONES

Consejo mandó en agosto de 1671 que para averiguar la realidad de la locura alegada para su defensa por el mercader trajinante portugués Pedro Rodríguez Ferro, de 44 años, residente en Madrid y preso en Toledo por judaísmo en septiembre de 1670 , se le diera por compañero a otro preso, Lázaro de Joseph, palestino. Se ordenó al alcaide y a su asistente que lo espiaran a todas horas sin que él se diera cuenta para poder 'hazer el juicio más azertado en su locura'. La misma orden se dio a los médicos. El 1 de octubre del año siguiente los inquisidores escribieron al Consejo que 'el reo está maníaco, loco, incapaz de razón y con necesidad precisa de curarse y de que para ello se lleve a la casa de los locos' ${ }^{37}$ Según orden de la Suprema del 3 de agosto, este reo fue puesto en una celda grande y con mucha luz y lo empezaron a visitar los médicos y el calificador del tribunal. Aunque unos y otros discrepaban sobre la realidad de su locura, varios médicos decían que estaba en su juicio natural y que lo que tenía era terquedad. También opinaban el alcaide de la cárcel y el compañero de celda del portugués que todo era fingido. ${ }^{38}$ En 27 de octubre de 1673 se votó que este reo saliera a auto público, se leyera su sentencia, abjurara formalmente y se confiscaran sus bienes, lo cual se ejecutó el domingo 11 de febrero de 1674 en que salió al auto con sambenito. ${ }^{39}$

Si el Consejo zanjó las dudas que tenía sobre la realidad de la locura de este reo con relativa facilidad, le costó mucho trabajo y muchos años averiguar qué pasaba con doña María de Robles, alias de la O., vecina de Madrid, presa en 7 de julio de 1673 por delitos y proposiciones heréticas formales, como el afirmar que no estaba obligada a confesarse, que no tenía pecados, que consideraba pecado humillarse al comulgar, que los sacramentos no eran medicina espiritual, que la penitencia sacramental la había de dar sólo Dios y no el cura. ${ }^{40}$ Calificadores y médicos declararon en enero del año siguiente que estaba totalmente alienada pero en mayo, su compañera de celda dijo que estaba en su juicio mientras que el alcaide, así como los médicos que la visitaron y los calificadores, opinaron lo contrario. ${ }^{41}$ En julio, después de hacerle muchas preguntas, dos calificadores resolvieron que estaba 'lesa de juicio o endemoniada'. ${ }^{42}$ Pero en octubre otras personas que estaban en las cárceles y la habían asistido declararon que decía muchas herejías y no era loca sino bellaca. A lo largo de los meses siguientes todos discreparon y manifestaron opiniones divergentes. ${ }^{43}$ En febrero de 1675 dos calificadores decían que la

37 AHN, Inq., leg. 3137, carta del 1 de octubre de 1671.

38 AHN, Inq., leg. 3138, 'Relación de las causas de fe, 4 de febrero de 1672'; leg. 3138, 'Relación de las causas de fe, 5 de septiembre de 1672'.

39 AHN, Inq., leg. 3139, 'Relación de las causas de fe, 24 de enero de 1673'.

40 AHN, Inq., leg. 3146, fols 11v-12r ('Relación de las causas de fe desde el 6 de junio hasta el 12 de septiembre de 1681 ').

41 AHN, Inq., leg. 3140, 'Relación de las causas de fe de junio de 1674'.

42 AHN, Inq., leg. 3140, 'Relación de las causas de fe de septiembre de 1674'.

43 AHN, Inq., leg. 3140, 'Relaciones de causas de fe de enero, febrero de 1675'. 
tenían 'por grabemente sospechosa y que procede con malicia en quanto dice para ebadirse del castigo' ${ }^{44}$ Los inquisidores votaron en discordia sobre el modo de proseguir y se remitió la causa al Consejo, quien ordenó que fuera ingresada en la casa de los locos y se encargara a los médicos del tribunal la visitasen y al administrador de la casa observara sus acciones y diera cuenta de su opinión acerca de su juicio.

María de Robles ingresó en el Hospital del Nuncio el 10 de junio de $1675 .{ }^{45}$ En mayo de 1676 la visitó un médico del tribunal y declaró que la rea estaba en su juicio. Los inquisidores mandaron a un calificador que tuviese conferencia con ella y avisase del estado de su juicio. ${ }^{46} \mathrm{En}$ marzo del año siguiente, este último, que había ido muchas veces a verla, no tenía ninguna certidumbre y opinaba que 'avía raçón prudencial de dudar si era fisión su locura o no' ${ }^{47}$ En junio afirmaba que 'aún no hace juicio determinado de que no es loca y le hasse probable de que es malicia por exsimirse del castigo'. Todos en el hospital, administrador y enfermera inclusive, dudaban de si estaba loca o no: el médico opina en octubre de 1677 que padece 'melancolía morbo' y que es 'el mismo estado en que estaba en las cárceles secretas y en que salió a dicho Hospital del Nuncio y que assí está loca como siempre'. Asimismo declara haver estado con esta rea en conjunción de lunas y que al hablarla le respondió algunos disparates.$^{48}$ En octubre de 1678 el médico dice que está en el mismo estado 'y siempre con la tema de no dejarse tomar el pulso, [...]; dize y habla cosas fuera de propósito y si algo dize en conversación seguida, luego disparata' y el calificador declara en noviembre que 'haze juicio por las acciones exteriores que ha visto en esta rea [...], en el modo de mirar sobresaltado que tiene, puede ser padezca alguna manía ${ }^{49}$ En este momento ya nadie sabe a qué atenerse. El 15 de diciembre de 1678, el tribunal manda llamar al doctor Pedro Astorga, médico de cámara del mismo monarca, y le encomienda que la vea. Éste la visita varias veces a partir de enero de 1679 y acaba diciendo que es conveniente que la vea el doctor Gavino Fariñas, también médico de cámara de Su Majestad, lo cual se ejecuta sin que se llegue a conclusiones definitivas. El 13 de julio, el padre Durán, calificador del Santo Oficio de la orden de Santo Domingo, entrega un papel acerca del juicio de la rea en que concluye 'ser locura falssa y delirio finxido el suyo y ella fina herética y que se puede proceder jurisdiccionalmente en dicha caussa' ${ }^{50} \mathrm{El} 21$

\footnotetext{
AHN, Inq., leg. 3140, 'Relación de las causas de fe de abril de 1675'.

AHN, Inq., leg. 3140, 'Relación de las causas de fe de junio de 1675'.

AHN, Inq., leg. 3142, 'Relación de las causas de fe de mayo de 1676'.

AHN, Inq., leg. 3143, 'Relación de las causas de fe de marzo hasta mayo de 1677'.

AHN, Inq., leg. 3143, 'Relación de las causas de fe de noviembre de 1677'.

AHN, Inq., leg. 3144, 'Relación de las causas de fe de septiembre de 1678'.

sHN, Inq., leg. 3145, 'Relación de las causas de fe pendientes desde 12 de mayo hasta 22 de agosto
} de 1679'. 
ORIGINALES Y REVISIONES

de julio, fray Nicolás Sánchez, de la orden de San Francisco, guardián de San Juan de los Reyes y calificador del Santo Oficio, opina que:

esta rea o tiene algún demonio arrimadizo o es hereje proterva y que para conocer lo dicho, primero se le hagan exorcismos por persona ordenada y experta en la materia de conjuros respecto de ser más dificultoso el conocer el demonio arrimadizo que el que no lo es, y para lo segundo de si está tocada del crimen de herejía, el tribunal tomará providencia según las noticias antecedentes y que, aunque responde algunas palabras fuera de propósito, puede ser refugio para no gravarse. ${ }^{51}$

No sabemos si se llegaron a ejecutar dichos conjuros. Lo que sí se echa de ver es que cada vez se dudaba más de si estaba realmente loca. Así, en agosto de 1679, el administrador del hospital declaró que 'esta rea, además de no tener falta de juicio, el que tiene es con gran vellaquería y malicia, [...] que siempre ha estado y está con buena salud, durmiendo y comiendo bien a sus horas'. Lo mismo declara la enfermera mayor que comparte su habitación individual en el Hospital del Nuncio y la acompaña a todas horas. Con lo cual el tribunal votó en conformidad el 15 de septiembre que fuese traída a una cárcel secreta del Santo Oficio y se le asignase una compañera de capacidad que vigilara sus acciones, y que si continuara resistiéndose a declarar bajo juramento y a responder derechamente como lo había hecho hasta ahora, se le bajara a la cámara de tortura y se le amenazara con el potro, para poder evaluar su juicio y capacidad. ${ }^{52}$ Según la relación de causas de fe de octubre de 1688, la rea quedó detenida en el hospital. En este tiempo el médico opinó que su juicio era sano y bueno y la gente que la asistía declaró lo mismo y 'que sólo quando le hablan de Dios y de sus santos responde haciendo mofa y burla con muchos y graves ultrajes'. ${ }^{33}$ María de Robles falleció en el Hospital del Nuncio hacia 1689.

A la hora de disipar las dudas de los inquisidores, la opinión de médicos y cirujanos del tribunal resultaba también fundamental, como lo demuestra, por ejemplo, el citado caso de Ana de Acosta, judaizante, presa por el tribunal de Toledo en mayo de 1662. Las dudas de los inquisidores respecto de la locura de esta rea surgen en junio de 1663 cuando, por fin curada del pie y más cuerda, le sobreviene 'un tabardillo que la tiene muy postrada y en peligro de su vida' ${ }^{54}$ La quieren con-

51 AHN, Inq., leg. 3145, 'Relación de las causas de fe desde 12 de mayo hasta 22 de agosto de 1679'.

52 AHN, Inq., leg. 3146, 'Relación de las causas de fe pendientes desde el 5 de diciembre de 1679 hasta el 13 de febrero de 1680'.

53 AHN, Inq., leg. 3149, caja 1, 'Relación de las causas de fe pendientes de octubre de 1688', n 2.

54 AHN, Inq., leg. 3129, fols 2v-207r (fol. 159r). 
fesar antes de administrarle los sacramentos, pues temen que muera. Pero ella está extenuada y ni se mueve, ni habla. Es entonces cuando al calificador que intenta, en vano, sacarle siquiera una palabra, le empiezan a entrar algunas dudas: ¿y si estuviese fingiendo? Según afirma, el hecho mismo de que la enferma ni siquiera le quiera apretar la mano le deja con alguna sospecha.

El 15 de junio de 1663, el médico del Santo Oficio, catedrático de medicina en la Universidad de Toledo, se vale de un ardid increíble para obligarla a hablar: entra en su habitación con un brasero de lumbre con hierros, acompañado de un cirujano y varios ministros, fingiendo que le van a mutilar otros dedos del pie. Le aprietan con una cinta el tobillo del pie sano y le preguntan si quiere confesar. La desgraciada entonces no tiene más remedio que contestar que sí. Acto seguido acude un sacerdote para oírla en confesión y administrarle el sacramento de la eucaristía (fol. 162r.). Por la tarde el inquisidor, sin perder tiempo, viendo que Ana está en su juicio, la hace abjurar públicamente los delitos de herejía que ella había confesado en su proceso (fol. 163r.). Fue reconciliada, condenada a salir con los otros penitentes en hábito y a un año de cárcel y confiscación de bienes y después desterrada por tres años y condenada a llevar públicamente el sambenito (fols. 194 y siguientes).

El destino de Ana puede ser comparado con la resolución del caso de Beatriz de Campos, aquella conversa portuguesa judaizante a la que nos hemos referido con anterioridad, que estuvo enferma más de siete años. ${ }^{55}$ Parece que los inquisidores dudaban acerca del carácter verdadero o fingido de su falta de cordura, pues no cesaban de tomar declaración a quienes cuidaban de ella como si temiesen que los engañara. Destaca el hecho de que, no obstante haber sido encarcelada en diciembre de 1678 y declarada loca de remate en abril de 1679, y a pesar de su manifiesta y ruidosa demencia, no la ingresaron en el Hospital del Nuncio hasta febrero de 1680. Primero la dejaron en situación de observación. Sólo a partir de agosto de 1683 los que se ocupan de ella en el hospital declaran que la enferma parece estar mejorando. Lo que llama la atención es que para demostrar esa recuperación, el rector del hospital afirma que Beatriz de Campos acude a misa, ha pedido licencia para confesarse y le ha insistido para que pida audiencia en su nombre. Llamada ante el tribunal, la enfermera mayor del Hospital de Nuncio afirmó que de los tres años y medio en que la mujer estuvo recluida en dicha casa, se mostró como una demente furiosa durante un año y medio; después mejoró y ahora iba a misa con regularidad y era un ejemplo de devoción. En las conversaciones que tiene con ella, 'siempre trata de cossas de Dios y espirituales' y todo lo que le dice es 'con manifestación de muy buena christiana' (fols. 120v-121v). De todo ello concluyen

\footnotetext{
55 AHN, Inq., leg. 138, caja 1, exp. 9, fols. 71r-194r.
} 
ORIGINALES Y REVISIONES

que tiene 'buena capacidad y entendimiento', que está en su completo y sano juicio. Comprobamos pues cómo en las mentalidades inquisitoriales se equiparaban ortodoxia religiosa y cordura de los reos, y al contrario, herejía y locura, pudiendo ser ésta fingida, lo que para ellos acentuaba más la maldad de los acusados. Mandan al alcaide vaya a la casa de locos y la traiga al tribunal para darle audiencia. Se sabe que la rea fue reconciliada en el hospital y que, después, considerada curada, concluyó el proceso y fue condenada el 24 de abril de 1686 a salir en auto de fe, abjurar, sambenito, cárcel perpetua y confiscación de bienes.

Los casos estudiados testimonian que la Inquisición necesitaba que el hospital de locos respaldara su actuación. Por lo tanto solicitaba muy a menudo su colaboración. ¿Cuál fue la posición del cabildo de Toledo, del que dependía el Hospital del Nuncio, ante los 'locos' inquisitoriales? ${ }^{56}$

\section{Relaciones entre la Inquisición de Toledo y el Hospital del Nuncio}

Los administradores de los hospitales no siempre vieron con buenos ojos a los locos suplementarios que les enviaba la Inquisición. ${ }^{57}$ Por ejemplo, la correspondencia entre los inquisidores de Toledo y el Consejo Supremo de la Inquisición atestigua que en la segunda mitad del siglo XVI esta cuestión suscitó constantes desavenencias entre los inquisidores y el cabildo de la iglesia. En una petición de abril de 1570 dichos eclesiásticos se habían quejado de que los inquisidores enviaban a muchos reos y que éstos no siempre estaban locos. Un mes después, en una carta al Consejo, los inquisidores protestan afirmando que los presos que ellos enviaron a este hospital fueron muy pocos y que todos eran locos de verdad que habían perdido el juicio en la cárcel. Así mismo solicitan no tener que pedir permiso al cabildo para enviar dementes a dicho hospital. Esta carta, además, deja entrever una cierta conflictividad latente entre inquisidores y canónigos cuando no una lucha por la autoridad y hasta francas enemistades: los inquisidores se niegan a pedir permiso al calbido aduciendo que 'sería de mucho inconveniente esperar los términos del cabildo quanto más que esto es invención de gentes que de todo punto aborreçen el

56 AHN, Sobre la administración del Hospital del Nuncio por el cabildo, véanse Francisco de B. San Román, Autobiografía de Francisco Ortiz y constituciones del Hospital del Nuncio, de Toledo (Madrid: Imprenta de Ramona Velasco, viuda de P. Pérez, 1932), 21; Ricardo Saez, Recherches sur le clergé castillan et les mentalités religieuses en Espagne à l'époque moderne (1550-1621). Le cas de l'archevêché de Tolède, (Paris: Université París III, 1997), III, 787-832; véase también Saez, 'Le corps reclus et souffrant dans l'univers hospitalier du siècle d'or, l'exemple tolédan', in Le corps dans la société espagnole des XVIème et XVIIème siècles, ed. Augustin Redondo (Paris: Publications de la Sorbonne, 1990), 153-164 (p. 159).

57 Sobre las protestas que los administradores del Hospital General de Valencia dirigieron a los inquisidores en el siglo XVII, véase Hélène Tropé, Locura y sociedad, 203-204. 
nombre de Inquisición' ${ }^{58}$ La respuesta del Consejo fue que no mandaran al Hospital del Nuncio a persona alguna sin que primero se les informara.

Bien es verdad que, como hemos visto, la cuestión de la veracidad de la locura de los reos se planteaba incesantemente a los inquisidores, siempre muy preocupados por averiguar si los reos se habían vuelto locos de verdad o si fingían su locura para intentar librarse del castigo. Sea como fuere, en más de una ocasión, el rector de este hospital escribió a los inquisidores para señalar que tal o cual reo enviado por el tribunal no estaba loco. Por ejemplo, un año antes de la referida petición del cabildo de la ciudad, en agosto de 1569, el rector de dicho hospital había pedido audiencia al tribunal y había atestiguado que un preso francés, Juan Ubal, enviado ahí para su curación, estaba en realidad perfectamente cuerdo según el parecer de todo el personal de dicha casa. En su carta dicho rector se queja de que este reo esté ahí 'y coma la limosna que está dedicada para personas locas'.59

Estas desavenencias se manifestaron otra vez en 1574 cuando mediante el mismo rector, el cabildo de la iglesia hizo saber a los inquisidores su rechazo a recibir a un reo en el Hospital del Nuncio, Francisco Tirado, alegando que en dicha institución no había hacienda para sustentar a más de cuarenta enfermos de locura y que en este momento no había plaza vacante para recibir a otra persona. Los inquisidores protestaron afirmando que se había de recibir al loco aunque no hubiese lugar vacío pues la Casa del Nuncio era rica y lo podía asumir perfectamente. El rector del hospital fue convocado ante el tribunal y acabó reconociendo que en el año y medio que había estado ahí, hallándose ya cuarenta locos en el hospital, había visto recibir a otros internos supernumerarios. Los inquisidores informaron de inmediato, el 22 de abril, al Consejo, quien ordenó que los inquisidores instaran a los administradores del hospital a recibir a dicho reo. ${ }^{60}$

58 AHN, Inq., leg. 3070, exp. 21: 'Los inquisidores de 3 de mayo recebida en Madrid a 6 del mismo sobre la petición del cabildo de la santa iglesia de la ciudad de Toledo. Resebida en Madrid a VI de mayo 1570. [...] lo que en esto pasa es bien diferente de lo que en la petición se dize porque an sido muy pocos los que desta Inquisición se an embiado a la casa del Nuncio y estos locos y muy locos porque aunque quando se prendieron tenían buen seso le perdieron en esta cárcer y fue forçado el llevallos al hospital del Nuncio a curar y en entendiendo tienen salud, los bolbemos acá y aquella casa es muy rica y para sólo este efecto de curar locos y ningún agravio resçibe con que le embiemos allí alguno y mandamos al rector de la dicha casa y hospital que le resçiba porque a averse de tratar con el cabildo, fuera de perderse autoridad, sería nunca acabar y el que enloqueçe en estas cárceres tiene nesçesidad de remedio muy presto por el mal aparejo que aquí ay para tenelle ny curalle y sería de mucho inconveniente esperar los términos del cabildo quanto más que esto es invención de gentes que de todo punto aborreçen el nombre de Inquisición y ansí no pareçe que en esto deva aver novedad ni alteraçión alguna. Vuestra Señoría mandará lo que más fuere servido'.

59 AHN, Inq., leg. 3069, exp. 180, fols 1r-5v.

${ }^{60}$ AHN, Inq., leg. 3071, exp. 157, exp. 158 y exp. 160 (Toledo, 22 de abril de 1574); véase también AHN, Inq., libro 1231, fol. 91v, rúbrica 'Presos', n 10: 'Que compelan al Rector del Nuncio reciva a un loco'. 
ORIGINALES Y REVISIONES

Sugestivo al respecto es también el caso de Guillermo Keith, escocés de 69 años, que fue preso el 8 de agosto de 1578 por criticar la actuación de la Inquisición con los herejes. Absuelto en un primer momento por su locura y enviado al Hospital del Nuncio, hizo ahí mil desatinos durante ocho meses hasta que intentó huir. El Consejo mandó en noviembre de 1579 que se le encerrara de nuevo en las cárceles secretas y se iniciara su causa pero en otra carta de enero de 1580 los inquisidores insistieron en que era 'un viejo bárbaro sin juicio ni discurso alguno' y que 'bolvelle a estas cárceles no serviría más que de dar costa al fisco y ocupar este tribunal con mil impertinencias y pesadumbres y desasosegar los presos ${ }^{61}{ }^{61}$ En el hospital debió de permanecer y quizás acabar este preso sobre el que no encontramos más noticias.

Según otra carta de los inquisidores toledanos al Consejo, el problema se planteó nuevamente en febrero de $1588 .{ }^{62}$ Querían ingresar en el manicomio a César Calvino, luterano vecino de Madrid, natural del Piamonte, que se había vuelto loco furioso y estorbaba sobremanera en las cárceles por sus gritos pero el rector alegababa que no había plaza libre y que se consultase con el cabildo. Se sabe por el Manuscrito de Halle que finalmente los inquisidores votaron para que se le diera el tormento (cordel y potro) y después lo enviaron al hospital de locos. ${ }^{63}$

Otra vez, en unas cartas de 9 y 23 de febrero de 1606, los inquisidores informaron al Consejo que, siguiendo sus instrucciones, habían ingresado desde octubre de 1606 a un reo que estaba muy loco, Alonso Roldán de Salazar, en el Hospital del Nuncio pero que, según el rector y los canónigos del cabildo, no había plaza vacante en aquel momento y no se sabía cuándo la habría. Además, para la primera que se liberara, el monarca tenía enviado a un enfermo que había de ingresar. Por lo tanto, los canónigos habían puesto como condición que el tribunal diera dos reales cada día para su mantenimiento. ${ }^{64}$ Alegaban que el Santo Oficio tenía que pagar, pues siempre pagaba Su Majestad cuando se le recibía algún enfermo en plaza supernumeraria. ${ }^{65}$ El Consejo contestó que los inquisidores avisaran del estado en que se hallaba y de si, soltándolo y dejándolo vivir con su mujer después de amenazarlo, estaría con más sosiego y añadió que no quería se cargaran los gastos de mantenimiento a la Inquisición.

En cuanto al morisco Iñigo de Carvajal, zapatero de Almagro, cuya reclusión en el Hospital del Nuncio había ordenado el Consejo el 26 de octubre de 1606

${ }^{61}$ AHN, Inq., leg. 3073, exp. 27, exp. 80 y exp. 85; leg. 3074, exp. 4; véase también Sierra, Procesos en la Inquisición de Toledo, caso ${ }^{\circ} 134$.

62 AHN, Inq., leg. 3076, exp. 49.

63 Sierra, Procesos en la Inquisición de Toledo, causas vistas fuera de auto desde el 7 de marzo de 1601 al primero de abril de 1602 , caso $n^{\circ} 976$.

${ }^{64}$ Sobre el ingreso y la estancia de Alonso Roldán de Salazar en el Hospital del Nuncio, véase AHN, Inq., leg. 3085, exp. 55 (carta del 26 de octubre de 1606). También exp. 76 y exp. 83 (cartas del 9 y del 23 de febrero de 1607 respectivamente).

65 AHN, Inq., leg. 3085, exp. 83 (carta del 23 de febrero de 1607). 
(ejecutándose el 4 de noviembre), el rector informó pronto que estaba en su buen juicio y que no hacía cosa alguna de loco, pero eso sí, 'ceremonias de la secta de Mahoma' que causaban escándalo en los que entraban en el manicomio. Por lo visto, lo sacaron y lo devolvieron a las cárceles secretas pero el 24 de junio de 1608 lo enviaron otra vez al hospital y se ordenó al rector que lo observara para saber 'si haçía acciones de loco y que si hiçiesse algunas çeremonias de la secta de Mahoma, le açotasse y castigasse para que no las volviesse a haçer'. El mismo reo dijo que no tenía necesidad de más cura que de la que hacía el tribunal y que hacía más de un año que no practicaba ceremonias. Además, confesaba que estaba muy arrepentido. Estuvo en el hospital más de seis meses, al cabo de los cuales los rectores informaron que ya no hacía ni locuras ni ceremonias y se avergonzaba cuando se decía que había sido moro. Era mantenido a costa del fisco, con lo cual, a los inquisidores les parecía que sería conveniente comiera en las cárceles secretas y se acabara su causa. ${ }^{66}$ Según otra carta del 12 de mayo de 1609 lo llevaron otra vez a las cárceles secretas. Fue admitido a reconciliación con hábito y cárcel perpetua y confiscación de bienes en auto público. ${ }^{67}$

Vislumbramos a través de estos casos lo embarazoso que podían llegar a ser aquellos reos dementes a quienes los inquisidores no lograban mantener quietos en las cárceles secretas y a los que el cabildo, de quien dependía el Hospital del Nuncio, tampoco quería recibir ni alimentar gratuitamente.

Es significativo que el cabildo recordara a los inquisidores, en 1624, que 'la dicha casa era de ospitalidad para pobres locos y no para reclusión perpetua por ser contra la constituçión de dicho ospital, prinçipalmente no asigurando los gastos y alimentos que se abían de dar [...]'. ${ }^{68}$ De la correspondencia entre los inquisidores toledanos y el Consejo acerca del ingreso de los presos en el Hospital del Nuncio en la segunda década del siglo XVII se deduce que el cabildo seguía mostrándose muy reticente a la hora de recibir y alimentar presos de la Inquisición en el hospital: nunca había plaza vacante para éstos y si, a instancias del tribunal, se aceptaba algún reo en plaza supernumeraria, era con la condición de que se pagara dos reales cada día por cada persona y una fanega de trigo cada mes, si bien, a veces, parece que el Hospital del Nuncio aceptó recibir a reos locos por sólo un real cada día. ${ }^{69}$ Si el preso era pobre, tenía que pagar el fisco, razón por la cual el tribunal decidía a veces devolver a los reos orates a sus familiares con la orden de que cuidaran de

66 AHN, Inq., leg. 3086, carta del 18 de febrero de 1609.

67 AHN, Inq., leg. 3086, carta de 12 de mayo de 1609.

68 AHN, Inq., leg. 3098, carta del 20 de julio de 1624.

69 AHN, Inq., leg. 3098, carta de 27 de julio de 1624: 'la respuesta que el dicho cabildo a dado es que lo reçibirán dando cada día dos reales y cada mes una anega de trigo. A [nosotros] nos pareçe mucho porque en otras ocasiones nos an reçibido otros dando cada día un real no más'. 
ORIGINALES Y REVISIONES

ellos y se las arreglaran para que no escandalizaran, como pasó por ejemplo en 1623 en el caso de Bernardo de Asmendia, natural de Canabas en Cataluña, vecino de Madrid, preso por proposiciones heréticas y considerado 'desmentado', 'yncapaz y falto de juiçio', y 'pobre'.$^{70}$ Pero no se encontró a su mujer y al final, la Suprema ordenó que se lo enviaran para ingresarlo en otro hospital de locos. ${ }^{71}$ En realidad, en el Nuncio escaseaban las plazas para recibir a los reos con tales dolencias y por lo tanto había que guardar las pocas que había para presos considerados realmente peligrosos, como por ejemplo Fernando de Fernández. Este clérigo presbítero y cura del obispado de Palencia había sido arrestado en Toledo en enero de 1622 por proposiciones heréticas expresadas durante sus sermones y por afirmar que él, por parte de padre, era de generación divina. ${ }^{72}$ Lo reputaron por loco y acordaron fuese puesto en una casa de locos hasta que se curase. ${ }^{73}$ No encontramos más noticias de él.

El tribunal toledano no siempre estaba dispuesto a pagar lo que le exigía el cabildo para mantener a estos enfermos en el Hospital del Nuncio. En una ocasión, en agosto de 1638, con el motivo de que el fisco de la Inquisición de Toledo estaba muy empeñado y no podía pagar los sesenta y ocho ducados exigidos cada año para mantener a Adán Caravallo en dicho hospital, los inquisidores pidieron a la Suprema que este reo fuese llevado al Hospital de los locos de Nuestra Señora de Gracia de la ciudad de Zaragoza. ${ }^{74}$ Otros presos del tribunal toledano también estuvieron en ese mismo hospital en el siglo XVII: Gaspar Méndez de Vaeza, portugués natural de Porto Alegre, preso por judaísmo en una fecha que desconocemos, confesó, después revocó y mientras revocaba, enloqueció y se llevó a dicho hospital donde murió el 20 de marzo de 1641. Se acordó fuese reconciliado en estatua en auto público de la fe y se confiscaran sus bienes. ${ }^{75}$

70 AHN, Inq., leg. 3097, carta del 3 de octubre de 1623: '[...] y por haver pareçido hombre falto de juiçio y desmentado, se había suspendido su causa y mandó se entregase a su muger para que cuydase de él y no escandaliçase con los disparates que diçe, que aunque nos pareçía estuviera mejor en la casa del Nunçio desta çiudad, no lo avemos mandado poner en ella por no haver plaça baca y aunque pudiera en plaça supernumeraria hera con mucha costa porque se pagase cada persona dos reales cada día y una anega de trigo cada mes, lo cual sería de mucho costo para el fisco aviéndolo de pagar [este último] por ser pobre el dicho Bernardo de Asmendia [...]'.

71 AHN, Inq., leg. 3097, carta del 10 de noviembre de 1623 [respuesta de la Suprema]: 'que le embíen aquí para que se encamine a alguna otra casa de los locos'.

72 AHN, Inq., leg. 3097, carta del 10 de noviembre de 1623: 'y el aguardar a que aya plaza baca podría pasar mucho tiempo y sería más a propósito cuando la ubiesse para Fernando de Fernández, clérigo presbítero, presso en las cárceles secretas'.

73 AHN, Inq., leg. 3092, 'Relación de las causas de fe despachadas de 1618'.

74 AHN, Inq., leg. 3108, carta de 9 de agosto de 1638.

75 AHN, Inq., leg. 3113, 'Relaçión de las causas de fe pendientes del 29 de henero de 1644': 'También anda en relaçión el proçesso de Gaspar Méndez de Baeza, portugués, natural de Porto Alegre en Portugal. Este fue preso por judío observante de la ley de Moysen y en una de sus audiençias, confesó las culpas del judaísmo y en otra relaçión sus confesiones y estando revocante enloqueçió y se dementó y se llevó este preso por mandado de los señores inquisidores al hospital de los locos de Zaragoça'. 
En diciembre de 1679 había cuatro dementes en el Hospital de los locos toledano por orden del Santo Oficio: las reas arriba mencionadas, doña María de Robles y Beatriz de Campos, y los reos Thomás Castellanos y don Francisco Bazán. ${ }^{76}$ Hacia febrero de 1681, María de Robles ocupaba una de las 40 plazas de enfermos mentales asumidos por el Hospital del Nuncio cuando se consideró que ya no estaba loca. El Consejo ordenó que fuera devuelta a las cárceles secretas, y el arcediano de Toledo accedió a que aunque unos locos estaban aguardando desde antes para ingresar en el lugar de la rea en la casa de orates, se diera la plaza que quedase vacante a un preso demente designado por el Santo Oficio. ${ }^{77}$ Por lo tanto, los inquisidores estaban haciendo las diligencias correspondientes con el cabildo para que uno de los tres perturbados asumidos por el Santo Oficio en el hospital, se quedase con la vacante. Así se evitaría el gasto elevado que representaba el mantenimiento de dichos presos ahí: 'dos reales y medio cada día y otro de cama y vestir y fanega de trigo cada mes' ${ }^{78}$ En una carta al Consejo del 11 de julio de 1689 los inquisidores aluden a la plaza vacnte que dejó María de Robles al morir en el Hospital del Nuncio, y que se cedió a Juan de Espinosa, loco pobre (procesado por el tribunal por haber celebrado misa no estando ordenado), cuyos familiares, madre y hermanos, habían certificado que no podían pagar a la casa de locos los tres reales diarios y la fanega de trigo al mes que se les pedía para su mantenimiento. ${ }^{79}$ Según parece, poco a poco, las relaciones entre inquisidores y cabildo habían ido mejorando notablemente.

76 AHN, Inq., leg., 3146, 'Relación de las causas de fe pendientes desde el 5 de diciembre de 1679 hasta el 13 de febrero de 1680', véase el folio final sin numerar: 'los reos presos son 56 y otros cinco detenidos de la complicidad de Pastrana y quatro que se consideran en estado de locos, o incapaces por ahora de seguir el juicio'; AHN, Inq., leg. 3146, 'Relación de causas de 4 locos, febrero de 1681'; AHN, Inq., leg. 3146, 'Relación de las causas de fe desde 28 de enero hasta 6 de junio de 1681', fol. 12r; AHN, Inq., leg. 3146, 'Relación desde el 6 de junio hasta el 12 de septiembre de 1681 ', fol. $13 \mathrm{r}$.

77 AHN, Inq., leg., 3146, 'Relación de las causas de fe pendientes desde el 5 de diciembre de 1679 hasta el 13 de febrero de 1680', fol. 1r; AHN, Inq., leg. 3146, 'Relación de las causas de fe que están pendientes desde el día 13 de febrero hasta el día 20 de agosto deste año de 1680'; AHN, Inq., leg. 3146, fols 11v-12r; AHN, Inq., leg. 3146, 'Relación de las causas de fe pendientes desde el 20 de agosto hasta el 20 de octubre de 1680, fol. $15 \mathrm{v}, \mathrm{n}^{\circ}$ 67; AHN, Inq., leg. 3146, $\mathrm{n}^{\circ}$ 64, 'Relación de las causas de fe pendientes desde el veinte de octubre de 1680 hasta el 20 de 1681 ', fol. $21 \mathrm{v}-22 \mathrm{r}, \mathrm{n}^{\circ} 64$.

78 AHN, Inq., leg. 3145, exp. 4, 'Relación de las causas de fe que están pendientes desde el día 13 de febrero hasta el día 20 de agosto deste año de 1680'. [margen]: 'Loco, proposiciones, Pedro de Paiva'; AHN, Inq., leg. 3146, 'Relación de causas de cuatro locos, febrero de 1681' [...]. 'Estos tres detenta el fisco a gran costa de dos reales y medio cada día y otra de cama y vestir y fanega de trigo cada mes'.

79 AHN, Inq., leg. 3150, caja 1, 'Relación de las causas de fe desde 24 de noviembre de 1690', fol. 3r, $n^{\circ}$ 11.AHN, Inq., leg. 3149, caja 2, 'Información sobre el estado en que se halla el Licenciado Juan de Espinosa que está en el Hospital del Nuncio (julio de 1689)'; AHN, Inq., leg. 3149, caja 2, 'Con el proceso contra el Lizenciado Juan de Espinosa (septiembre de 1689)'. 